\title{
O LUTO FAMILIAR PELO DIAGNÓSTICO DO TRANSTORNO DO ESPECTRO AUTISTA NA VISÃO PSICANALÍTICA
}

\author{
Alberto de Jesus Vidal ${ }^{1}$ \\ Isabella Silva de Andrade ${ }^{2}$ \\ Gerson Heidrich da Silva ${ }^{3}$
}

RESUMO: O presente estudo teve por finalidade fazer uma revisão bibliográfica sobre o luto familiar trazido pelo diagnóstico do transtorno do espectro autista. Neste, é trazida a compreensão das formas desse espectro, e também a maneira que a família enfrenta essa situação, levando em consideração as fases desse luto como culpa, raiva, barganha, depressão e aceitação. Quando um casal gera um filho, diversas situações circundam esse momento: são criadas esperanças, projetos e uma ansiedade que toma conta dos futuros pais. Criam, nesse momento, expectativas favoráveis sobre o bebê, gerando assim uma ideia de perfeição ou de criança perfeita. No entanto, ao perceberem a diferença de seu bebê em relação a outros considerados típicos, os pais geralmente buscam por um profissional para possíveis esclarecimentos e algum diagnóstico. Frente ao diagnóstico do transtorno de espectro autista (TEA), os processos de luto são iniciados. Este estudo apresentará, então, aspectos de direcionamento quanto ao entendimento do espectro autista e seu diagnóstico, além de outras condições do espectro como o luto e sua elaboração, o papel do psicólogo e formas de tratamento na perspectiva psicanalítica.

Palavras-chave: Transtorno de Espectro Autista. Psicanálise. Luto.

ABSTRACT: This term paper aimed to make a bibliographic review on family grief brought by the diagnosis of autism spectrum disorder. In this, the understanding of the forms of this spectrum is brought, as well as the way the family faces this situation, considering the phases of this mourning such as guilt, anger, bargaining, depression, and acceptance. When a couple generates a child, several situations surround this moment: expectations are created; projects and an anxiety dominate the future parents. At that moment, they create favorable expectations about the baby, thus generating an idea of perfection or of a perfect child. However, when parents perceive the difference of their baby in relation to others considered typical, parents usually look for a professional for possible clarifications and some diagnosis. Faced

\footnotetext{
I Formado em Psicologia pela Universidade de Santo Amaro e concluinte do Curso de Prevenção ao Suicídio pela Secretaria do Estado da Saúde do Paraná (SESA) ofertado pela Universidade Federal do Rio Grande do Norte.

${ }^{2}$ Formada em Psicologia pela Universidade de Santo Amaro, tendo como experiência atuação na área de pesquisa, através do acompanhamento terapêutico de pacientes com TEA em ambiente clínico, escolar e domiciliar. E-mail: isa_andradeapci6@hotmail.com.

${ }^{3}$ Psicólogo, doutor em Educação pela Faculdade de Educação da USP, professor e supervisor do curso de psicologia da Universidade Santo Amaro - UNISA. Contato: psicopiq@gmail.com.
} 
with the diagnosis of autistic spectrum disorder (ASD), the grieving processes are initiated. This study will then present guiding aspects regarding the understanding of the autistic spectrum and its diagnosis, in addition to other conditions of the spectrum such as mourning and its elaboration, the role of the psychologist and forms of treatment in the psychoanalytic perspective.

Keywords: Autism Spectrum Disorder. Psychoanalysis. Mourni.

\section{INTRODUÇÃO}

A partir do momento em que se observa uma diferença na padronização do desenvolvimento de um filho, trazendo a possibilidade de um diagnóstico de Transtorno do Espectro Autista (TEA), os pais, como forma de resistência, geralmente não consideram esse diagnóstico como verdade. Ao contrário, por meio da negação, acabam tentando ocultar para si mesmos a realidade que está por ser manifesta. E, quando essa verdade vem à tona, o que resta aos pais é um potente impacto que desestruturará suas bases emocionais, causando-lhes irreparáveis estendidos à família. Terão de unir forças para se estabilizar, enfrentar os desafios futuros e, de alguma forma, conviver com esse transtorno.

De acordo com o DSM-V (2014), o Autismo ou Transtorno de Espectro Autista (TEA) como é conhecido, devido comportar Transtorno de Asperger, Transtorno Desintegrativo da Infância e Transtorno de Rett, é uma síndrome de origem multicausal que envolve fatores neurológicos, sociais e genéticos da criança. Comprometendo o seu desenvolvimento motor e psiconeurológico, acarreta dificuldades na linguagem, cognição e interação social.

Szimanski (20iI) fala sobre a importância da família, observando que as crianças começam a compreender o mundo em sua volta, constituindo a sua identidade e seu desenvolvimento por meio das relações familiares, quando a família se torna o principal modelo referencial para seus filhos. Desse modo, em relação ao autismo, Marques e Dixe (20II) entendem que as mudanças na família se tornam um fato, trazendo, além de implicações, novos significados à vida. Há a perspectiva de fortalecimento dos laços afetivos, trazendo alento e renovo para que a vida siga de certa maneira como uma missão. Adaptar-se à nova realidade passa a ser, então, parte fundamental da experiência. 
Segundo Freud (1915), o luto tem por características a perda de um elo significativo entre uma pessoa e seu objeto, sendo esse um fenômeno mental natural e corriqueiro durante o desenvolvimento dos seres humanos. Ainda segundo o autor, a ideia de luto não está limitada apenas à morte, mas também ao enfrentamento das perdas constantes, sejam elas reais ou simbólicas. Já Melanie Klein (1940) converge com Freud em relação à explicação do luto, mas faz um complemento ao compreender o luto também como uma perda objetal, acrescentando que o luto não diz respeito somente a uma perda objetal real, porém também simbólica.

Falando especificamente do luto familiar trazido por um diagnóstico, Franco (2015) aponta um pathos no luto vivido pelos pais, consequente do nascimento de uma criança com deficiência, que entende a paixão inicial que os pais atribuem ao bebê, o qual pode aparecer como obstáculo no processo de elaboração do luto, devido à perda da criança idealizada.

Para a elaboração do luto, Kübler-Ross (2008) diz que é necessário vivenciar cinco estágios, quais sejam: a negação, a raiva, a barganha, a depressão e a aceitação, os quais não acontecem necessariamente nessa ordem, mas que são importantes para essa elaboração. Aqui podemos pensar o papel do psicólogo, o qual segundo Souza et al (2004), se faz necessário para ajudar na promoção de uma vida mais digna, mais amena e proveitosa às crianças e familiares inseridos no contexto.

Por fim, em relação às abordagens psicológicas, existe uma gama de estudos relacionados à psicanálise sendo aplicada nas tratativas do TEA. É neste sentido que este estudo foi desenvolvido, buscando uma atualização do que é preconizado pela psicanálise, no que se refere ao processo de elaboração do luto motivado pelo diagnóstico do TEA.

\section{METODOLOGIA}

O método de pesquisa utilizado foi a revisão bibliográfica, que segundo Brasileiro (2003), é aquela que recorre a publicações científicas em periódicos, livros, anais de congressos etc., além de ter por finalidade sintetizar pesquisas qualitativas. No caso deste trabalho, os resultados estão baseados na revisão de artigos que correspondem ao período de 1986 a 2017 , além de livros sobre o tema. 
Para a coleta de material, foram utilizados alguns critérios como o próprio tema e as variáveis temáticas, sendo realizadas essas buscas nas seguintes bases de dados:

Scielo e PepSic (Portal BVS). Os descritores utilizados foram: Autismo, TEA, Diagnóstico, Infância, Família, Luto, Elaboração do Luto, Papel do psicólogo, Tratamento, Psicanálise. Foram encontrados um total de 15 artigos, sendo selecionados 8 de acordo com os seguintes critérios de inclusão: resumos que estavam relacionados com os subitens da pesquisa. Os artigos excluídos foram 7, pois na leitura do resumo percebeu-se que não havia relação com a proposta.

\section{RESULTADOS E DISCUSSÃO}

Foram utilizados para a discussão 8 artigos, conforme Quadro I a seguir, além de 8 livros temáticos que constam nas referências bibliográficas.

\section{Quadro I - Artigos utilizados para discussão}

\begin{tabular}{|c|c|c|c|}
\hline $\begin{array}{l}\text { Base / } \\
\text { Ano }\end{array}$ & $\begin{array}{c}\text { Tipo de } \\
\text { Publicação }\end{array}$ & Titulo Original & Autores \\
\hline $\begin{array}{c}\text { Scielo, } \\
2011\end{array}$ & Artigo & Sobre a escolha do sujeito autista & CATÃO, I. e VIVES J. M. \\
\hline $\begin{array}{l}\text { Scielo, } \\
2014\end{array}$ & Artigo & $\begin{array}{r}\text { O processo de luto no contexto do } \\
\text { API-ES: aproximando } \\
\text { narrativas } \\
\end{array}$ & DAVEL, Alzira. Et. Al \\
\hline 1986 & Artigo & $\begin{array}{l}\text { Ajudando adolescentes } \\
\text { enlutados: necessidades e } \\
\text { respostas }\end{array}$ & FLEMING, S.J., \& ADOLPH, R \\
\hline $\begin{array}{l}\text { Scielo, } \\
2015\end{array}$ & Artigo & $\begin{array}{c}\text { Paixão-dor-paixão: Pathos, luto e } \\
\text { melancoliano nascimento da criança } \\
\text { com deficiência }\end{array}$ & FRANCO, Vitor \\
\hline $\begin{array}{l}\text { Scielo, } \\
2017\end{array}$ & Artigo & $\begin{array}{c}\text { Transtornos do espectro do autismo e } \\
\text { psicanálise }\end{array}$ & GONÇALVES, Amanda. Et. al \\
\hline 2009 & Artigo & $\begin{array}{l}\text { Os obejtos autísticos } \\
\text { complexos são nocivos? }\end{array}$ & MALEVAL, Jeaan \\
\hline $\begin{array}{l}\text { Scielo, } \\
2 \text { oII }\end{array}$ & Artigo & $\begin{array}{c}\text { Crianças e jovens autistas: } \\
\text { Impacto na } \\
\text { Dinâmica Familiar e Pessoal de } \\
\text { seus } \\
\text { pais. }\end{array}$ & MARQUES, M.H e DIXE, M.A.R \\
\hline $\begin{array}{l}\text { Scielo, } \\
2004\end{array}$ & Artigo & $\begin{array}{c}\text { Atuação do psicológo frente aos } \\
\text { Transtornos globais do } \\
\text { desenvolvimento infantil } \\
\end{array}$ & SOUZA, José. Et, al \\
\hline
\end{tabular}

\section{ANÁLISE DOS RESULTADOS}

Após o levantamento dos resultados acima, por meio da revisão bibliográfica, foi possível compreender melhor como se dá o processo do luto familiar ao receber o diagnóstico de um filho com TEA.

O luto desde as mais antigas civilizações é visto como um mal sobre o qual 
evitamos falar, ocorrendo uma tendência de negar a morte e outras perdas que trazem o luto. Fleming e Adolf (1986) acreditam que alguns indivíduos tendem a suprimir e rejeitar o luto, pois se torna indigno e sinônimo de fraqueza de caráter.

Porém, Freud (1915) diverge ao explicar que o luto é o rompimento de um elo entre pessoa e um objeto de libido, o que nos faz considerar esse luto partindo da perda de algo ou alguém que nos é importante. Com isso, percebemos o luto como o processo de transformação e compreensão de um fenômeno causado pela separação do objeto de importância para cada sujeito, não algo a ser evitado.

Melanie Klein (1940) nos faz refletir no pressuposto do luto, partindo da ideia de que é a perda objetal que dá significância ao mesmo. Assim, para Freud e Klein, a experiência do luto se inicia desde a infância, no começo do desenvolvimento psíquico humano. Desse modo, tais colaborações sobre o luto se mostram como pontos de convergência entre os autores.

Entretanto, falando especificamente da perda em relação a um filho, Davel e Silva (2014) também mencionam que todas as perdas que ocorrem durante a vida do ser humano, desde a perda de um emprego a uma doença ou perda de um filho, seja no real ou no simbólico, como no caso de pais com filhos autistas, promovem um grande desgaste físico e emocional, que gera um luto em relação às expectativas criadas.

Segundo Freud (1920), o término do luto se dá com o prevalecimento da realidade. Exige-se que seja retirada a libido que fora depositada naquele objeto, assim a elaboração do luto se concretiza dando a possibilidade de uma vida mais amena por parte do indivíduo que retorna a sua forma original, sem a ligação de tal objeto.

Já Kübler-Ross (2008) considera que para haver uma elaboração do luto, é necessária a passagem por alguns estágios, sendo eles: a negação, a raiva, a barganha, a depressão e a aceitação. Sendo assim, podemos pensar que a autora tenha nomeado por estágios esse desinvestimento libidinal que Freud (1920) menciona.

A partir da elaboração do luto, em relação ao papel do psicólogo, segundo Souza et. Al, (2004), este deve ser inserido no contexto familiar e da pessoa com TEA, tendo uma formação específica e bem definida, ou seja, um conhecedor do desenvolvimento humano típico. Esse fato propicia condições de uma compreensão das áreas comprometidas pelo transtorno e suas consequências na pessoa e família, usando de 
sensibilidade às observações e relatos da família.

$\mathrm{Na}$ elaboração do luto, em relação às abordagens psicológicas, existe uma gama de estudos relacionados à psicanálise sendo aplicada no tratamento de TEA. Segundo Gonçalves et al. (2017), as principais formas de realização desse tratamento se dividem em quatro categorias: o manejo da transferência; a reestruturação psíquica através do simbólico; ênfase no jogo simbólico e a aquisição da linguagem. Além das quatro categorias mencionadas anteriormente, a prática clínica mostra que se manter com uma postura "surda" ao se direcionar à criança ocasiona uma angústia, que é diminuída pelos objetos autísticos, os quais, segundo Tustin (1975), estão ligados ao próprio fechamento autístico, pois não são utilizados de acordo a função, mas sim como uma segurança em relação à ameaça de aniquilação. Entretanto, Maleval (2009) traz um ponto de divergência, ao explicar que a função desses objetos consiste em situar o gozo sobre a borda, ou seja, sobre os limites, possibilitando assim a diminuição das automutilações, as quais são muito comuns em autistas.

Portanto, nota-se que há de fato um luto ao receber um diagnóstico de um filho, porém há caminhos como mostrado nos resultados coletados que possibilitam a elaboração desse luto, como algumas fases que serão vivenciadas pelo enlutado: a negação, a raiva, a barganha, a depressão e a aceitação.

É preciso considerar, no entanto, que no caso dos pais de crianças autistas, de acordo com Franco (2015), não se trata apenas de um desinvestimento libidinal, mas também de um investimento na criança que "ficou", a qual não foi a idealizada, surgindo assim questões como: “O que fazer com essa “outra” criança?”.

Neste sentido, o papel do psicólogo torna-se fundamental no processo de elaboração desse luto, considerando as fases apontadas e a necessidade de investimento nas potencialidades dessas crianças. Segundo Souza et al (2004), o psicólogo poderá ajudar na promoção de uma vida mais digna e proveitosa para as crianças diagnosticadas com o Transtorno de Espectro Autista e seus familiares, a partir de um processo de desidealização de um objeto supostamente perfeito: a criança idealizada.

Importante ressaltar que Catão \& Vivès (20II) quando dizem que o tratamento voltado para crianças com o Transtorno de Espectro Autista, sob o olhar da Psicanálise, impulsiona a uma saída dessa posição de fechamento autístico, desde que 
o psicólogo se coloque como um Outro que não seja tão presente e que não demande muito, atuando pelo o que a criança traz, a legitimando. É escutar essa criança, mesmo com suas poucas palavras, ecolalias ou ausência de manifestação verbal, atentando para os sons e gestos que emitidos constituem sua própria voz.

\section{CONSIDERAÇÕES FINAIS}

Diante das pesquisas realizadas, utilizando-se da metodologia de revisão bibliográfica, ficou claro que ocorre de fato um processo de luto dos pais de crianças diagnosticadas com o Transtorno de Espectro Autista. Isso se deve às fantasias e expectativas criadas ao se ter um filho e, ao perceber que a criança nasceu não de acordo aos seus desejos narcisistas, os pais, diante dessa frustração, terão de vivenciar um processo de elaboração desse luto.

Essa elaboração passa por fases como a negação diante do diagnóstico, a raiva de ter sido "escolhido" para passar por essa situação, a barganha com as promessas em troca de uma benção divina, a depressão quando os pais já se encontram esgotados diante da situação e, quando conseguem chegar, a aceitação ao encarar a realidade e ser capaz de lidar melhor com o fato.

Além dessas etapas, ficou evidente que a elaboração desse luto também passa pelo laço criado com essa criança, e o tratamento pela psicanálise pode auxiliar nesse enlace com o sujeito autista. Assim, entende-se que se faz necessário um psicólogo na equipe multidisciplinar, desde que este tenha condições de uma percepção das áreas comprometidas pelo transtorno e suas consequências na criança e família.

Logo, compreende-se que para a Psicanálise, o Transtorno do Espectro Autista não é uma doença a ser curada e nem um comportamento a ser adequado, mas sim um transtorno que acomete sujeitos que têm seu próprio funcionamento. Cabe, então, ao profissional psicólogo oferecer escuta às crianças com Transtorno de Espectro Autista, atento às suas peculiaridades, pois a criança nessa condição apenas tem uma maneira diferente de lidar com o Outro.

Essa escuta profissional também precisa ser oferecida à família, o que poderá resultar em uma melhora da qualidade de vida do portador do Transtorno do Espectro Autista, bem como da sua família e até da equipe multidisciplinar. Ou seja, todos 
podem ajudar na construção de um novo caminho, especialmente o psicólogo, que trabalhará com os sentimentos e expectativas de todos, favorecendo elaborações que poderão resultar na desidealização de um objeto até então idealizado, a criança perfeita, tornando possível uma relação menos dolorosa frente às vicissitudes da vida.

\section{REFERÊNCIAS}

AMERICAN PSYCHATRIC ASSOCIATION. Manual de diagnóstico e estatístico de transtornos mentais - DSM V. $5^{\circ}$ Edição. Porto Alegre: Artmed, 2014.

BRASILEIRO, Ada. Manual de produções de textos acadêmicos e científicos. São Paulo: Atlas, 2013.

CATÃO, Inês; VIVÈS, Jean. Sobre a escolha do sujeito autista: voz e autismo. Estudos de Psicanálise. Belo Horizonte, n.36, p. 83- 92, dez. 2011.

DAVEL, Alzira; SILVA, Daniela. O processo de luto no contexto do API-ES: aproximando as narrativas. Revista Pensando Família. Rio Grande do Sul, vol. I8, n I, jun. 2014.

FLEMING, S.J., \& ADOLPH, R. Ajudando adolescentes enlutados: necessidades e respostas. In C.A. Corr \& J.N. McNeil (Eds.), (pp. 97-II8). New York, NY: Springer. 1986.

FRANCO, Vitor. Paixão-dor-paixão: pathos, luto e melancolia no nascimento da criança com deficiência. Revista Latinoamericana de Psicopatologia Fundamental. São Paulo, v. I8, n. 2, p. 204-220, jun. 2015.

FREUD, Sigmund. Luto e melancolia (1917 [1945]). A história do Movimento Psicanalítico, Artigos sobre a Metapsicologia e outros trabalhos (1914-1916). Edição Standard Brasileira das Obras Psicológicas Completas de Sigmund Freud. Vol. XIV. Rio de Janeiro: Imago, 1996.

FREUD, Sigmund. Além do Princípio de Prazer (1920). Psicologia de Grupo e outros trabalhos (1920-1922). Edição Standard Brasileira das Obras Psicológicas Completas de Sigmund Freud. Vol. XVII. Rio de Janeiro: Imago, 1996.

GONÇALVES, Amanda et al. Transtornos do espectro do autismo e psicanálise: revisando a literatura. Revista Tempo Psicanalítico. Rio de Janeiro, v. 49, n. 2, p. 152I8I, dez. 2017.

KLEIN, Melanie. O luto e suas relações com os estados maníaco-depressivos (1940). Amor, culpa e reparação e outros trabalhos (1921-1945). Obras Completas de Melanie Klein. Vol I. Rio de Janeiro: Imago, 1996. 
KÜBLER-ROSS, Elisabeth. Sobre a morte e o morrer: o que os doentes terminais têm para ensinar a médicos, enfermeiros, religiosos e aos seus próprios parentes. São Paulo: Martins Fontes, 2008.

MALEVAL, Jean. Os objetos autísticos complexos são nocivos? Psicologia em Revista. Belo Horizonte, v.15, n. 2, p. 223-254, 2009.

MARQUES, Mario; DIXE, Maria. Crianças e Jovens autistas: Impacto na Dinâmica Familiar e Pessoal de seus pais. Revista Psiquiatria Clínica. São Paulo, v. 38, n. 2, p. 66-70, 2011.

SOUZA, José. Atuação do psicólogo frente aos transtornos globais do desenvolvimento infantil. Revista Psicologia: Ciência e Profissão. Brasília, v. 24, n. 2, p. 24-eI, jun. 2004.

SZYMANSKI, Heloisa. A relação família/escola: Desafios e perspectivas. $2^{a}$ Edição. Brasília: Liber livro. 20II.

TUSTIN, Frances. Autismo e Psicose Infantil. São Paulo: Imago, 1975. 